\title{
Factor VII deficiency rescues the intrauterine lethality in mice associated with a tissue factor pathway inhibitor deficit
}

\author{
Joyce C.Y. Chan, ${ }^{1,2,3}$ Peter Carmeliet, ${ }^{1}$ Lieve Moons, ${ }^{1}$ Elliot D. Rosen, ${ }^{2,3}$ Zhong-Fu Huang, ${ }^{4}$ \\ George J. Broze, Jr., ${ }^{4}$ Désiré Collen, ${ }^{1}$ and Francis J. Castellino ${ }^{2,3}$ \\ ${ }^{1}$ Center for Transgene Technology and Gene Therapy, Flanders Interuniversity Institute for Biotechnology, B-3000 Leuven, Belgium \\ ${ }^{2}$ W.M. Keck Center for Transgene Research, and \\ ${ }^{3}$ Department of Chemistry and Biochemistry, University of Notre Dame, Notre Dame, Indiana 46556, USA \\ ${ }^{4}$ Division of Hematology, Washington University School of Medicine, Barnes-Jewish Hospital, St. Louis, Missouri 63110, USA
}

Address correspondence to: Francis J. Castellino, W.M. Keck Center for Transgene Research, and the Department of Chemistry and Biochemistry, University of Notre Dame, Notre Dame, Indiana 46556, USA. Phone: (219) 631-6456; Fax: (219) 631-8149;

E-mail: castellino.1@nd.edu

Or to: Désiré Collen, Center for Transgene Technology and Gene Therapy, Flanders Interuniversity Institute for Biotechnology, Campus Gasthuisberg, O\&N, Herestraat 49, B-3000 Leuven, Belgium. Phone: 32-16-34.57.80;

Fax: 32-16-34-60-01; E-mail: desire.collen@med.kuleuven.ac.be

Received for publication October 30, 1998, and accepted in revised form December 30, 1998.

\begin{abstract}
Mice doubly heterozygous for a modified tissue factor pathway inhibitor (TFPI) allele $\left(t f p i^{\delta}\right)$ lacking its Kunitz-type domain- $1\left(\mathrm{TFPI}^{+/ \delta}\right)$ and for a deficiency of the factor VII gene $\left(\mathrm{FVII}^{+/-}\right)$were mated to generate 309 postnatal and 205 embryonic day 17.5 (E17.5) offspring having all the predicted genotypic combinations. Progeny singly homozygous for the $t f p i^{\delta}$ modification but with the wild-type $f V I I$ allele $\left(\mathrm{FVII}^{+/+} / \mathrm{TFPI}^{\delta / \delta}\right)$, and mice singly homozygous for the $f V I I$ deficiency and possessing the wild-type $t f p i$ allele $\left(\mathrm{FVII}^{-/-} / \mathrm{TFPI}^{+/+}\right)$, displayed previously detailed phenotypes (i.e., a high percentage of early embryonic lethality at E9.5 or normal development with severe perinatal bleeding, respectively). Surprisingly, mice of the combined $\mathrm{FVII}^{-/ /} / \mathrm{TFPI}^{\delta / \delta}$ genotype were born at the expected mendelian frequency but suffered the fatal perinatal bleeding associated with the $\mathrm{FVII}^{-/}$genotype. Mice carrying the $\mathrm{FVII}^{+/}-\mathrm{TFPI}^{8 / \delta}$ genotype were also rescued from the lethality associated with the $\mathrm{FVII}^{+/+} / \mathrm{TFPI}^{\delta / \delta}$ genotype but succumbed to perinatal consumptive coagulopathy. Thus, the rescue of TFPI ${ }^{\delta / \delta}$ embryos, either by an accompanying homozygous or heterozygous FVII deficiency, suggests that diminishment of FVII activity precludes the need for TFPI-mediated inhibition of the FVIIa/tissue factor coagulation pathway during embryogenesis. Furthermore, the phenotypes of these combined deficiency states suggest that embryonic FVII is produced in mice as early as E9.5 and that any level of maternal FVII in early-stage embryos is insufficient to cause a coagulopathy in $\mathrm{TFPI}^{\delta / \delta}$ mice.
\end{abstract}

J. Clin. Invest. 103:475-482 (1999).

\section{Introduction}

Blood coagulation after vascular injury is initiated via the interaction of activated (a) factor VII (FVIIa) with its receptor and cofactor, tissue factor (TF). The resulting FVIIa/TF complex catalyzes activation of factors (F) IX and FX to FIXa and FXa, respectively, allowing for subsequent thrombin generation and, ultimately, the formation of a fibrin clot. While several anticoagulant proteins exist to downregulate different reactions of the coagulation system (e.g., activated protein $\mathrm{C}$, protein $\mathrm{S}$, heparin cofactor II, and antithrombin III), only tissue factor pathway inhibitor (TFPI) is known to inhibit the FVIIa/TF complex.

TFPI is a serine protease inhibitor that is composed of an acidic amino-terminus, followed by three tandem Kunitz-type proteinase inhibitory domains and a basic carboxy-terminus (1). Kunitz domain-1 (Ku1) binds the FVIIa/TF complex and inhibits FVIIa at its catalytic site, whereas Kunitz domain-2 (Ku2) is responsible for FXa inhibition (2). An inhibitory role for Kunitz domain-3 (Ku3) is yet to be elucidated, although positively charged residues in $\mathrm{Ku} 3$ and in the carboxy-terminus are known to be important for its binding to endothelial cells and other cell surfaces $(3,4)$. Inhibition of the FVIIa/TF complex involves the formation of a complex between TFPI, FVIIa, TF, and XXa. In this manner, TFPI mediates feedback inhibition of the initiation complex, but not before some FX is activated (5).

No documented cases of TFPI deficiency in humans have been described, suggesting that TFPI deficiency leads to embryonic lethality. However, TFPI deficiency has been induced in rabbits via immunodepletion, resulting in a sensitization to disseminated intravascular coagulation after endotoxin treatment or TF infusion $(6,7)$. Conversely, FVII deficiency is a rare autosomal recessive disease $(\sim 1$ in 500,000$)$ usually caused by a variety of identified mutations that affect antigen level, catalytic activity, or both. Depending on the severity of the disease and the speed of diagnosis, patients often succumb to hemorrhagic diathesis. Central nervous system hemorrhage occurs in 16\% of FVII-deficient patients (8). A murine model of total FVII deficiency has been generated via targeted deletion of the entire fVII gene (9). 
Mice homozygous for this gene inactivation $\left(\mathrm{fII}^{--}\right)$ developed normally through embryogenesis but suffered from severe perinatal bleeding, which greatly reduced their life span. This outcome was less severe than the phenotype observed in mice expressing a mutant form of TFPI, in which its Ku1 domain is missing (10). Embryos homozygous for this latter gene product $\left(\mathrm{TFPI}^{\delta / \delta}\right)$ died prematurely between embryonic day 9.5 (E9.5) and birth. Later-stage embryos perished of a consumptive coagulopathy, but the cause of early embryonic death in these cases has not been definitively established. Although it is tempting to speculate that these early-stage embryos also died of a consumptive coagulopathy, alternative mechanisms have not been ruled out, such as any unknown roles that TFPI may have owing to its production and localization on endothelial cells.

To gain further insight into the functions of FVII and TFPI, mice that were heterozygous for the $f V I I$ and $t f p i{ }^{\delta}$ alleles were bred. The phenotypic analysis of progeny resulting from this breeding is the subject of the current report.

\section{Methods}

Animals. The generation of mice heterozygous for the fVII (9) and $t f p i \delta(10)$ genes, in C57Bl/6 x 129SVJ murine backgrounds, has been described. The specific FVII-deletion construction consisted of a replacement of exons 2 to 8 of the fVII gene (11) with a neomycin phosphotransferase (neo) gene, thus eliminating all coding regions of the fVII gene. Modification of the $t f p i$ gene involved replacement of portions of exon 4 and intron $\mathrm{D}$ with the neomycin phosphotransferase gene (10). The resulting mature protein is then deleted of the Ku1 domain of TFPI. Mice doubly heterozygous for $f V I I$ and $t f p i{ }^{\delta}\left(\mathrm{FVII}^{+/-} / \mathrm{TFPI}^{+/ \delta}\right)$ were generated by cross-mating $\mathrm{FVII}^{+/}$with $\mathrm{TFPI}^{+/ \delta}$ mice.

Genotypic analysis. Genomic DNA was isolated from tail tips or from portions of embryonic yolk sacs, as described previously (12). For the analysis of $f V I I$ genotype, a 1.2-kb DNA fragment isolated after digestion of the FVII targeting vector (pND.FVII) with EcoRI and HindIII was randomly labeled with $\alpha-\left[{ }^{32} \mathrm{P}\right] \mathrm{dCTP}$ using a Rediprime DNA labeling kit (Amersham Life Sciences Inc., Arlington Heights, Illinois, USA). Digestion of genomic DNA with EcoRI and subsequent Southern hybridization resulted in the detection of a 10.5 -kb band for the wild-type $f V I I$ allele and a 6.1-kb band for the recombined $f V I I$ allele (9). $t f i^{\delta}$ genotypes were determined by PCR amplification. In this latter case, three primers were simultaneously used to detect both wild-type and mutant tfpi alleles, namely, $\mathrm{P}_{\mathrm{F}}$ from exon 4 (GAGCTGGGGTCAATGAAACCGCTGC), $P_{B 1}$ from exon 4 (ACACTCTTCCAGGGTATCAAATCGG), and $P_{\mathrm{B} 2}$ from the neomycin resistance gene (ACTTCCTGACTAGGGGAGGAGTAGA). Amplification of the wild-type allele produces a 170-bp fragment, whereas amplification of the mutant allele results in detection of a 330-bp fragment.

Timed matings. Doubly heterozygous females were placed with nonsibling doubly heterozygous males in the late afternoon. The morning of vaginal plug detection was assigned E0.5. Females were sacrificed, and the embryos were harvested at the appropriate time points. Yolk sacs from early-stage embryos or tails of later-stage embryos were dissected for DNA isolation. E9.5 to E14.5 embryos were fixed overnight in freshly prepared $1 \%$ phosphate-buffered paraformaldehyde. Embryos were then dehydrated and paraffin-embedded. Otherwise, organs were dissected and fixed in freshly prepared $1 \%$ phosphate-buffered paraformaldehyde. For postnatal analysis, litters were observed on a daily basis.
Several litters were sacrificed immediately after birth.

Histology. Paraffin-embedded organs were sectioned according to standard protocols. Sections were stained with hematoxylin and eosin (H\&E) (13) or immunostained for detection of von Willebrand factor (vWF), $\alpha$-actin, and fibrin(ogen) (14). For negative controls in these experiments, staining was performed in the absence of primary antibody.

Northern bybridization analysis of $t$ pi $m R N A$. Total RNA was isolated from pooled embryonic yolk sacs and adult organs using Trizol reagent (Life Technologies Inc., Gaithersburg, Maryland, USA). Samples were homogenized first in Trizol reagent, then extracted with $\mathrm{CHCl}_{3}$. RNA was precipitated from the aqueous phase with isopropanol. After centrifugation, the pelleted RNA was resuspended in $\mathrm{RNase}$-free $\mathrm{H}_{2} \mathrm{O}$ and stored at $-20^{\circ} \mathrm{C}$. Total RNA was subjected to electrophoresis on a denaturing agarose gel and transferred to a nylon membrane. The murine tppicDNA and the control murine hprt (hypoxanthine-guanine phosphoribosyl transferase) cDNA were radiolabeled with $\alpha-\left[{ }^{32} \mathrm{P}\right] \mathrm{dCTP}$ and used as probes for Northern hybridization.

Measurement of FVII activity. Blood was collected in citrate from embryos via direct cardiac puncture. After centrifugation at 3,000 $\mathrm{rpm}$ for $10 \mathrm{~min}$, plasma was collected and stored at $-20^{\circ} \mathrm{C}$ until analysis. Factor VII activity was measured via the Coatest FVII assay, as described by the manufacturer (Chromogenix, Brussels, Belgium). A volume of $50 \mu$ l of plasma, diluted in $50 \mathrm{mM}$ Tris- $\mathrm{HCl}$ ( $\mathrm{pH} 7.4), 0.2 \% \mathrm{BSA}$, was preincubated in a microtiter plate at $37^{\circ} \mathrm{C}$ for $4 \mathrm{~min}$. Samples were incubated for another $7 \mathrm{~min}$ at $37^{\circ} \mathrm{C}$ after the addition of $\mathrm{CaCl}_{2}(6.7 \mathrm{mmol}), \mathrm{FX}(0.014 \mathrm{U})$, and diluted thromboplastin. The chromogenic substrate S-2765 (50 $\mu$ l of a $0.94 \mathrm{mM}$ solution) was then added and incubated in the sample wells at $37^{\circ} \mathrm{C}$ for an additional $2 \mathrm{~min}$. The rate of release of the $P$ nitroaniline was measured at a wavelength of $405 \mathrm{~nm}$.

Measurement of TFPI activity. TFPI activity was measured in citrated plasma samples via the Actichrome TFPI assay as described by the manufacturer (American Diagnostica, Greenwich, Connecticut, USA). Diluted plasma (1:20 or 1:40, vol/vol, in TFPI-depleted plasma) was incubated with an equal volume of the FVIIa/TF complex at $37^{\circ} \mathrm{C}$ for $30 \mathrm{~min}$ in a microtiter plate. Human FX $(0.2 \mu \mathrm{g})$ was then added, and the reaction was further incubated at $37^{\circ} \mathrm{C}$ for $15 \mathrm{~min}$. After addition of EDTA ( $1 \mathrm{mM}$, final concentration) and Spectrozyme fXa substrate ( $0.5 \mathrm{mM}$, final concentration), the absorbance was measured at a wavelength of $405 \mathrm{~nm}$ at 5 -min intervals.

\section{Results}

Generation of $\mathrm{FVII}^{+/-} / \mathrm{TFPI}^{+} / \delta$ mice. Mice carrying the $\mathrm{FVII}^{+/}$ genotype were crossed with those with the $\mathrm{TFPI}^{+/ \delta}$ genotype to generate doubly heterozygous animals. Mice possessing the combined $\mathrm{FVII}^{+/-} / \mathrm{TFPI}^{+/ \delta}$ genotype appeared healthy and bred normally.

Characterization of offspring from double heterozygous matings. A total of 309 mice from the double heterozygous matings were generated. This group consisted of all offspring, including those that were sacrificed for experimentation, discovered dead, or partially consumed. Of the nine possible genotypes that could be generated from these crosses, all were present at approximately the expected mendelian distribution except progeny carrying the $\mathrm{FVII}^{+/+} / \mathrm{TFPI}^{\delta / \delta}(22 \%$ of expected $)$ and $\mathrm{FVII}^{+/-} / \mathrm{TFPI}^{\delta / \delta}$ (52\% of expected) genotypes (Table 1). A total of $65 \%$ of singly homozygous $\mathrm{FVII}^{-/}$- mice were found postnatally, consistent with previous observations 
Table 1

Distribution of $\mathrm{FVII} / \mathrm{TFPI}^{\delta}$ genotypes and plasma activities derived from cross-matings of $\mathrm{FVII} /$ - and $\mathrm{TFPI}^{+/ \delta}$ mice

\begin{tabular}{|c|c|c|c|c|c|c|c|c|c|}
\hline & $\begin{array}{l}\mathrm{FVII}^{+/+} / \\
\mathrm{TFPI}^{+/+}\end{array}$ & $\begin{array}{l}\mathrm{FVII}^{+/+} / \\
\mathrm{TFPI}^{+/ \delta}\end{array}$ & $\begin{array}{l}\mathrm{FVII}^{+/-} / \\
\mathrm{TFPI}^{+/+}\end{array}$ & $\begin{array}{l}\mathrm{FVII}^{+/-} / \\
\mathrm{TFPI}^{+/ \delta}\end{array}$ & $\begin{array}{l}\mathrm{FVII}^{+/+} / \\
\mathrm{TFPI}^{\delta / \delta}\end{array}$ & $\begin{array}{l}\mathrm{FVII}^{+/-} / \\
\mathrm{TFPI}^{\delta / \delta}\end{array}$ & $\begin{array}{l}\mathrm{FVII}^{-/-} / \\
\mathrm{TFPI}^{\delta / \delta}\end{array}$ & $\begin{array}{l}\mathrm{FVII}^{-/-/} \\
\mathrm{TFPI}^{+/ \delta}\end{array}$ & $\begin{array}{l}\mathrm{FVII}^{-/-/} \\
\mathrm{TFPI}^{+/+}\end{array}$ \\
\hline $\begin{array}{c}\text { Postnatal }{ }^{\mathrm{A}} \\
\text { E17. } 5^{\mathrm{A}}\end{array}$ & $\begin{array}{l}24 / 23(104 \%) \\
17 / 14(121 \%)\end{array}$ & $\begin{array}{c}57 / 46(124 \%) \\
27 / 28(96 \%)\end{array}$ & $\begin{array}{l}50 / 46(109 \%) \\
38 / 28(136 \%)\end{array}$ & $\begin{array}{l}77 / 92(84 \%) \\
48 / 56(86 \%)\end{array}$ & $\begin{array}{l}5 / 23(22 \%) \\
4 / 14(29 \%)\end{array}$ & $\begin{array}{l}24 / 46(52 \%) \\
26 / 28(93 \%)\end{array}$ & $\begin{array}{c}25 / 23(110 \%) \\
10 / 14(71 \%)\end{array}$ & $\begin{array}{l}32 / 46(70 \%) \\
24 / 28(86 \%)\end{array}$ & $\begin{array}{l}15 / 23(65 \%) \\
11 / 14(79 \%)\end{array}$ \\
\hline $\begin{array}{r}\text { TFPI activity } \\
6 \text { weeks }^{\mathrm{B}}\end{array}$ & $97 \pm 25$ & $53 \pm 9$ & $114 \pm 27$ & $63 \pm 9$ & ND & ND & ND & ND & ND \\
\hline $\begin{array}{l}\text { fVII activity } \\
6 \text { weeks }^{\mathrm{B}}\end{array}$ & $95 \pm 23$ & $96 \pm 9$ & $48 \pm 7$ & $54 \pm 9$ & ND & ND & ND & ND & ND \\
\hline $\begin{array}{c}\text { TFPI activity } \\
\text { E17.5 }\end{array}$ & $203 \pm 35$ & $170 \pm 66$ & $322 \pm 130$ & $148 \pm 61$ & $<0.01$ & $<0.01$ & $<0.01$ & $140 \pm 70$ & ND \\
\hline $\begin{array}{l}\text { fVII activity } \\
\text { E17.5 }\end{array}$ & $14.2 \pm 1.6$ & $8.95 \pm 3.6$ & $5.4 \pm 1.0$ & $3.65 \pm 0.92$ & $16.7 \pm 2.1$ & $5.7 \pm 1.2$ & $<0.05$ & $<0.05$ & $<0.05$ \\
\hline $\begin{array}{c}\text { TFPI activity } \\
\text { E11. } 5^{\mathrm{C}}\end{array}$ & $30 \pm 5$ & ND & ND & ND & ND & ND & ND & ND & ND \\
\hline
\end{tabular}

AThe number of animals [exhibiting/expected (\%)] of the indicated genotype out of a total of 370 postnatal and $231 \mathrm{E} 17.5$ mice. These totals were obtained by assuming that the observed number of $\mathrm{FVII}^{+/+} / \mathrm{TFPI}^{+/+}$, $\mathrm{FVII}^{+/+} / \mathrm{TFPI}^{+/ \delta}, \mathrm{fVII}^{+/-} / \mathrm{TFPI}^{+/+}$, and $\mathrm{fVII}^{+/-} / \mathrm{TFPI}^{+/ \delta}$ animals (which represents $9 / 16$ of all possible genotypes from these matings) were normal survival numbers. Thus, the total of these four genotypes represented $16 / 9$ of the total expected survivors. ${ }_{n} n=4-6$ for all animals examined. Activities are expressed as percentage of adult wild-type. CThe wild-type reference is pooled E11.5 wild-type plasma. E17.5, embryonic day 17.5; ND, not determined; TFPI, tissue factor pathway inhibitor.

(9). TFPI and fVII plasma activities were determined from six-week-old offspring bred from double heterozygous crosses (Table 1 ). The $\mathrm{TFPI}^{+/ \delta}$ animals possessed approximately $50 \%$ TFPI activity compared with their wild-type littermates in both $\mathrm{FVII}^{+/+}$and $\mathrm{FVII}^{+/}$- backgrounds. Heterozygosity at the $f V I I$ locus had no effect on TFPI activity. Similarly, $\mathrm{FVII}^{+/}$- heterozygotes possessed $50 \%$ of the fVII activity of $\mathrm{FVII}^{+/+}$animals in both $\mathrm{TFPI}^{+/ \delta}$ and $\mathrm{TFPI}^{+/+}$mice. The $\mathrm{FVII}^{-/}$mice were born at the expected frequency in all TFPI genotypic backgrounds (Table 1). These mice expired either immediately after birth from intra-abdominal hemorrhage or later in life from intracranial bleeding, as described earlier (9). Thus, the loss of TFPI activity (either $50 \%$ in $\mathrm{TFPI}^{+/ \delta}$ or $0 \%$ in $\mathrm{TFPI}^{\delta / \delta}$ animals) did not alter the pathologies of $\mathrm{FVII}^{-/-}$animals.

In contrast, the FVII genotype had a profound effect on the phenotype of TFPI ${ }^{\delta / \delta}$ mice. As reported previously (10), the $\mathrm{FVII}^{+/+} / \mathrm{TFPI}^{\delta / \delta}$ genotype was significantly underrepresented postnatally (Table 1). Those few neonates that survived embryogenesis expired during or immediately after birth. Macroscopically, skin color was dark purple and bruising was readily observable. These neonates also were always found after the initiation of necrosis; thus, histological interpretations would not be reliable and were not performed. Importantly, however, animals of the $\mathrm{FVII}^{-/-} / \mathrm{TFPI}^{\delta / \delta}$ genotype were born at the expected mendelian frequency (Table 1). These animals succumbed to the same fatal intra-abdominal or intracranial hemorrhaging as was the case for $\mathrm{FVII}^{-/-} / \mathrm{TFPI}^{+/+}$animals. The oldest of these latter mice survived to day 35 . Thus, it appeared that doubly homozygous $\left(\mathrm{FVII}^{-/-} / \mathrm{TFPI}^{\delta / \delta}\right)$ animals were rescued from the intrauterine lethality observed in the $\mathrm{FVII}^{+/+} / \mathrm{TFPI}^{\delta / \delta}$ embryos. Additionally, $\mathrm{FVII}^{+/-} / \mathrm{TFPI}^{\delta / \delta}$ mice were also born at a higher frequency than that of $\mathrm{FVII}^{+/+} / \mathrm{TFPI}^{\delta / \delta}$ mice (Table 1 ). These neonates were either found dead or died immediately after birth. Macroscopically, these mice were also purple and some contusions were again evident. Liquefication of the brain prevented histological analysis of that tissue; however, H\&E staining and antifibrin(ogen) immunostaining indicated hemorrhage (Fig. 1a) and diffuse fibrin deposition (Fig. 1b) in the interstitia of the liver. Hemorrhage was also observed in the kidneys (data not shown). Because the animals of this genotype were underrepresented, it was not clear whether a $50 \%$ level of FVII $\left(\mathrm{FVII}^{+}\right.$-) also resulted in a complete rescue of the intrauterine lethality of $\mathrm{TFPI}^{\delta / \delta}$ embryos. Once again, because necrosis had been initiated in these animals, the cause of death could not be reliably determined. Therefore, offspring of the double heterozygous matings were examined before birth.

Characterization of 17.5 embryos from double heterozygous matings. Timed matings allowed the harvesting of E17.5 embryos from double heterozygous crosses. Of 205 embryos, all the nine possible genotypes were generated at their expected mendelian frequencies except mice with the $\mathrm{FVII}^{+/+} / \mathrm{TFPI}^{\delta / \delta}$ genotype (29\%) (Table 1). These embryos frequently had shortened tails and a sunken cranial fontanel, as observed in the original tfpi gene modification study (10). On several occasions, the remnants of fetuses that had died in later gestation (between E14.5 and E17.5) were also observed, and invariably their genotypes were $\mathrm{FVII}^{+/+} / \mathrm{TFPI}^{\delta / \delta}$.

Contrary to the postnatal distribution data, embryos that were genotypically characterized as $\mathrm{FVII}^{+/-} / \mathrm{TFPI}^{\delta / \delta}$ were present at the expected frequency. This result demonstrates that a $50 \%$ level of fVII also leads to a rescue of the early intrauterine lethality observed in $\mathrm{FVII}^{+/+} / \mathrm{TFPI}^{\delta / \delta}$ embryos. Closer examination of these mice revealed obvious macroscopic abnormalities. Swelling on the head was clearly evident, and bleeding could be observed under the skull. Upon removal of the skin and puncture of the skull plate, a large volume of liquid exuded, resulting in an implosion of the skull plate. The brain still appeared intact after removal of the skull plate but was flattened, likely because of the pressure from the liquid (Fig. 1c). Immunostaining with $\alpha$ actin and vWF antibodies demonstrated normal brain vessel development (data not shown). Compared with wild-type mice (Fig. 1d), antifibrin(ogen) immunostaining demonstrated random vessel fibrin deposition 


\section{Figure 1}

( $\boldsymbol{a}$ and $\boldsymbol{b}$ ) H\&E staining (a) and antifibrin(ogen) immunostaining ( $b$ ) of adjacent $\mathrm{P} 0.5 \mathrm{FVII}^{+/-} / \mathrm{TFPI}^{\delta / \delta}$ liver sections indicating interstitial hemorrhage and diffuse fibrin deposition. (c) A top view of the brain from a $\mathrm{FVII}^{+/-} / \mathrm{TFPI}^{\delta / \delta} \mathrm{E} 17.5$ embryo after removal of the skin and skull plate, demonstrating pools of blood on top of an opaque flattened brain. $(\boldsymbol{d}-\boldsymbol{f})$ Antifibrin(ogen) immunostaining of a E17.5 wild-type $(d)$ or $\mathrm{FVII}^{+/-} / \mathrm{TFPI}^{\delta / \delta}$ brain $(e, f)$. Fibrin deposition (arrow) and initial brain matter degeneration is seen in $e$, further degeneration and fibrin deposition in $f$. $(\mathbf{g}) \mathrm{H} \& \mathrm{E}$ staining of the corresponding section shown in $f$ demonstrating hemorrhage. $(\boldsymbol{h}-\boldsymbol{j})$ Gross appearances of an E17.5 $\mathrm{FVII}^{+/+} / \mathrm{TFPI}^{\delta / \delta}$ embryo $(h)$ displaying growth retardation, bruising on the head, and the lack of a tail; of a E17.5 $\mathrm{FVII}^{+/-} / \mathrm{TFPI}^{\delta / \delta}$ embryo (i) with less severe growth retardation and bruising; and an E17.5 $\mathrm{FVII}^{-/-} / \mathrm{TFPI}^{\delta / \delta}$ embryo with normal appearance $(j)$. E17.5, embryonic day 17.5; $H \& E$, hematoxylin and eosin; TFPl, tissue factor pathway inhibitor.

throughout the brain tissue (Fig. 1e). Also, hemorrhage was observed in the vicinity of the occluded vessels of $\mathrm{FVII}^{+/-} / \mathrm{TFPI}^{\delta / \delta}$ mice by $\mathrm{H} \& \mathrm{E}$ staining. In some cases, the significant loss of white matter resulted in a transparentappearing brain, which was clearly evident histologically from antifibrin(ogen) (Fig. 1f) and H\&E (Fig. 1g) staining. Thus, the severity of liquefication varied greatly from brain to brain for this genotype. Immunostaining with vWF and $\alpha$-actin of heart, lungs, kidney, and liver tissue demonstrated normal organ development. Therefore, although $\mathrm{FVII}^{+/-} / \mathrm{TFPI}^{\delta / \delta}$ embryos are present at the expected frequency at E17.5, they also suffer from a consumptive coagulopathy that results in their death during or immediately after birth. That only $60 \%$ of the expected number of these mice are observed after birth is likely due to the immediate consumption of these neonates after death, a phenomenon also experienced in the fVII gene inactivation study (9).

In comparing the macroscopic appearance of the TFPI ${ }^{\delta / \delta}$ embryos at E17.5 with varying levels of FVII, it is noted that as the FVII level decreases from 100\% in the wild-type mice, to approximately $50 \%$ in the heterozygote, to $0 \%$ in the null, a "normalization" in the gross appearance of these TFPI ${ }^{\delta / \delta}$ embryos is observed, as revealed by increasingly longer tail sizes and diminished bruising (Fig. $1, b-j$ ).

Characterization of E9.5 to E14.5 embryos from double heterozygous matings. Earlier-stage embryos were harvested to examine the progression of the abnormalities in the $\mathrm{FVII}^{+/-} / \mathrm{TFPI}^{\delta / \delta}$ genotype. Although the TFPI ${ }^{\delta / \delta}$ embryos were rescued from early embryonic lethality by FVII heterozygosity, some of the $\mathrm{FVII}^{+/-} / \mathrm{TFPI}^{\delta / \delta}$ embryos demonstrated similar abnormalities as those that were often observed in $\mathrm{FVII}^{+/+} / \mathrm{TFPI}^{\delta / \delta}$ embryos at E9.5 (10).

Of the six $\mathrm{FVII}^{+/-} / \mathrm{TFPI}^{\delta / \delta}$ embryos examined, three demonstrated no signs of abnormalities, but the remainder appeared similar to embryos possessing the $\mathrm{FVII}^{+/+} / \mathrm{TFPI}^{\delta / \delta}$ genotype. Compared with wild-type E9.5 yolk sacs, these three abnormal $\mathrm{FVII}^{+/-} / \mathrm{TFPI}^{\delta / \delta}$ yolk sacs demonstrated a wide range of abnormalities, such as swollen capillaries, a lack of vitelline vessels, a coalescence of vessels to form pools of blood or "blood lakes," anemia, and in one case, a loss of blood circulation (Fig. 2a). The embryos, however, appeared normal. In contrast, approximately $50 \%$ of the $\mathrm{FVII}^{+/+} / \mathrm{TFPI}^{\delta / \delta}$ mice at this age exhib-
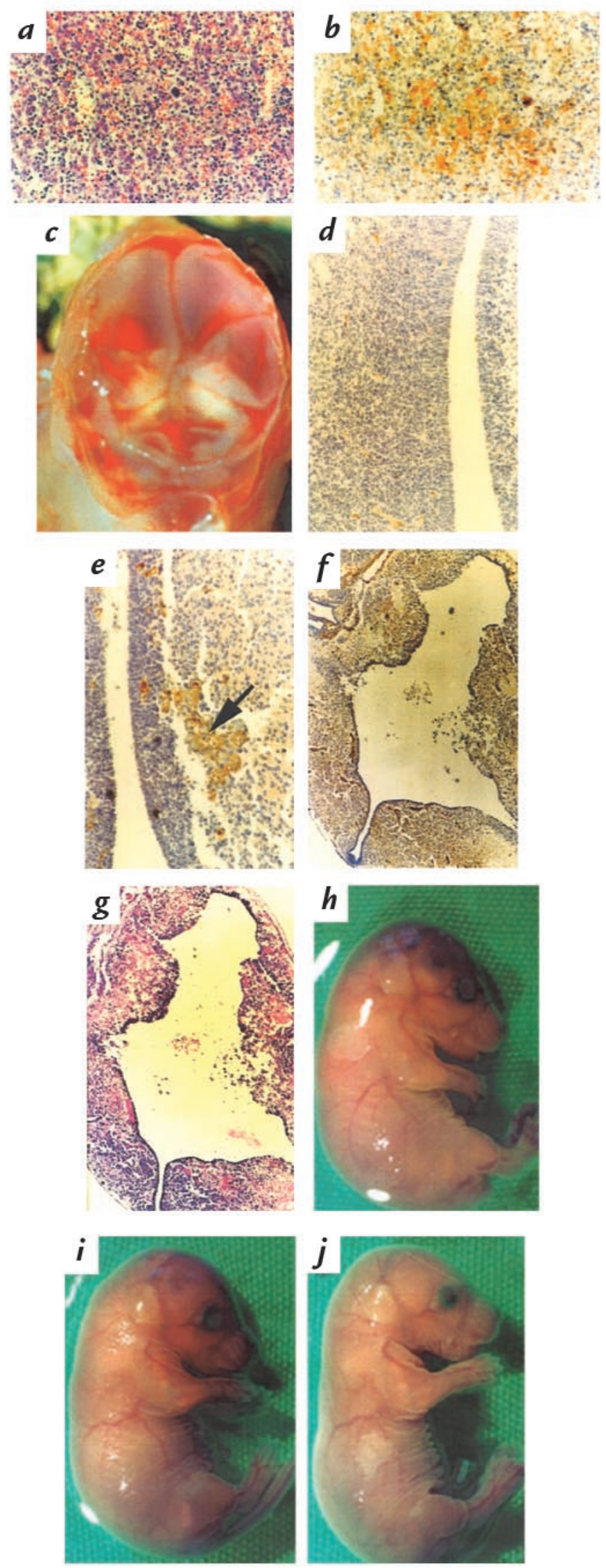

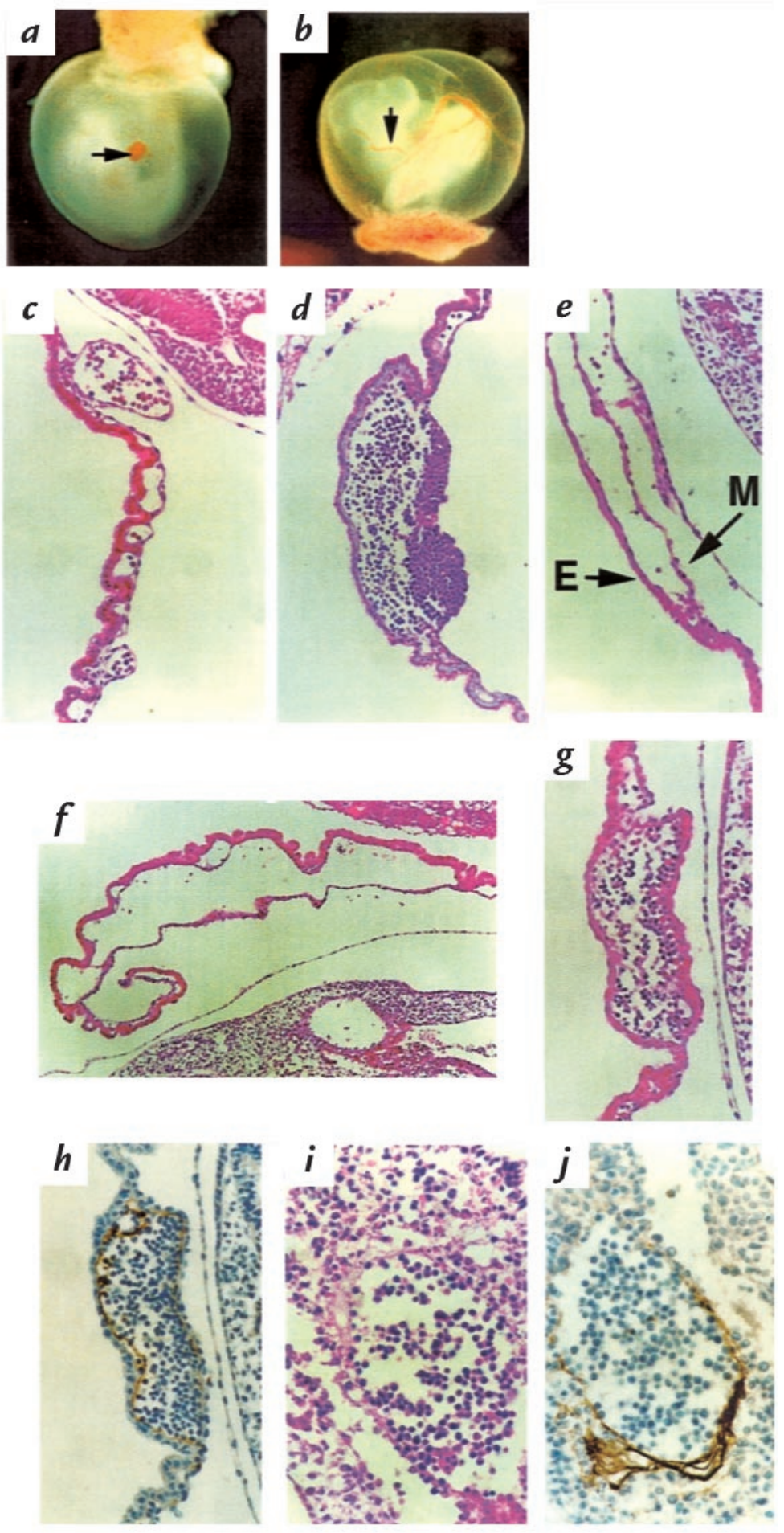

\section{Figure 2}

( $\boldsymbol{a}$ and $\boldsymbol{b}$ ) An E9.5 $\mathrm{FVII}^{+/-} / \mathrm{TFPI}^{\delta / \delta}$ embryo (a) surrounded by its yolk sac. The larger vitelline vessels are not readily apparent; the arrow points to a blood lake. An E9.5 normalappearing $\mathrm{FVII}^{-1-} / \mathrm{TFPI}^{\delta / \delta}$ embryo (b) surrounded by its yolk sac. The arrow points to a vitelline vessel in the normalappearing yolk sac. ( $\boldsymbol{c}-\boldsymbol{e}) \mathrm{H} \& \mathrm{E}$ staining of E9.5 yolk sacs. A $\mathrm{FVII}^{-/-} / \mathrm{TFPI}^{\delta / \delta}$ yolk sac section $(c)$ comparable in appearance to a wild-type yolk sac. A FVII ${ }^{+/+} / \mathrm{TFPI}^{\delta / \delta}$ yolk sac $(d)$ blood lake that contains red blood cells and further degeneration $(e)$, with separated yolk sac endoderm $(E)$ and mesoderm $(M)$ layers resulting in a lack of red blood cells in the disrupted vasculature. H\&E staining $(f)$ of an E10.75 $\mathrm{FVII}^{+/+} / \mathrm{TFPl}^{\delta / \delta}$ yolk sac showing further degeneration of endoderm and mesoderm contact and resulting anemia. $(\boldsymbol{g}-\boldsymbol{j}) \mathrm{H} \& \mathrm{E}$ staining $(\mathrm{g})$ of an $\mathrm{E} 10.75 \mathrm{FVII}^{+/+} / \mathrm{TFPI}^{\delta / \delta}$ yolk sac blood lake and antifibrin(ogen) staining of the parallel section (h), demonstrating fibrin deposition (gold) lining the interior of the blood lake. H\&E staining of a vessel within the corresponding embryo (i) and corresponding antifibrin(ogen) staining of the adjacent section (j), demonstrating fibrin deposition lining the interior of the vessel.

$2 c$ ). This differs from the wide array of abnormalities observed in the $\mathrm{FVII}^{+/+} / \mathrm{TFPI}^{\delta / \delta}$ genotype (Fig. 2, $d$ and $e$ ). No differences were observed in $\alpha$-actin staining between wild-type and the gene-modified embryos. Actin staining was prevalent in the hearts of both sets of these embryos, but it appeared minimally in the yolk sac, predominantly in the vessels closest to the yolk sac attachment to the placenta for all genotypes. However, staining was not observed in the majority of the yolk sac, including the aberrant vessels or blood lakes of the eight $\mathrm{FVII}^{+/+} / \mathrm{TFPI}^{\delta / \delta}$ or four $\mathrm{FVII}^{+/ /} / \mathrm{TFPI}^{\delta / \delta}$ embryos examined at E9.5 (not shown).

At E10.75, severe embryo abnormalities were observed in some $\mathrm{FVII}^{+/+} / \mathrm{TFPI}^{\delta / \delta}$ embryos to the point of necrosis. H\&E stainings revealed a degeneration of yolk sac structure, with separation of endoderm and mesoderm layers and subsequent anemia (Fig. 2f). Interestingly, in contrast to the original study describing single homozygous TFPI ${ }^{\delta / \delta}$ mice, in which fibrin was only detected at >E12.5 (10), fibrin was found lining the interior of a single blood lake (Fig. 2, $g$ and $h$ ) as well as within the embryo (vessel of yolk sac connecting embryo) (Fig. 2, $i$ and $j$ ) from only one of four $\mathrm{FVII}^{+/+} / \mathrm{TFPI}^{\delta / \delta}$ embryos examined. No fibrin deposition was found in any of the five $\mathrm{FVII}^{+/-} / \mathrm{TFPI}^{\delta / \delta}$ embryos examined.

Only a small number of animals with the $\mathrm{FVII}^{+/} / \mathrm{TFPI}^{\delta / \delta}$ genotype survived the early-stage lethality (Table 1). At E14.5, these embryos exhibit significant intracranial hemorrhage and edema and other random bleeding events on the skin. Although alive, they were severely anemic. Similarly, $\mathrm{FVII}^{+/-} / \mathrm{TFPI}^{\delta / \delta}$ embryos also presented with similar intracranial bleedings, whereas $\mathrm{FVII}^{-}-/ \mathrm{TFPI}^{\delta / \delta}$ embryos appeared like wild-type (Fig. 3, $a-c)$. Hemorrhage was confirmed in the brains of both 

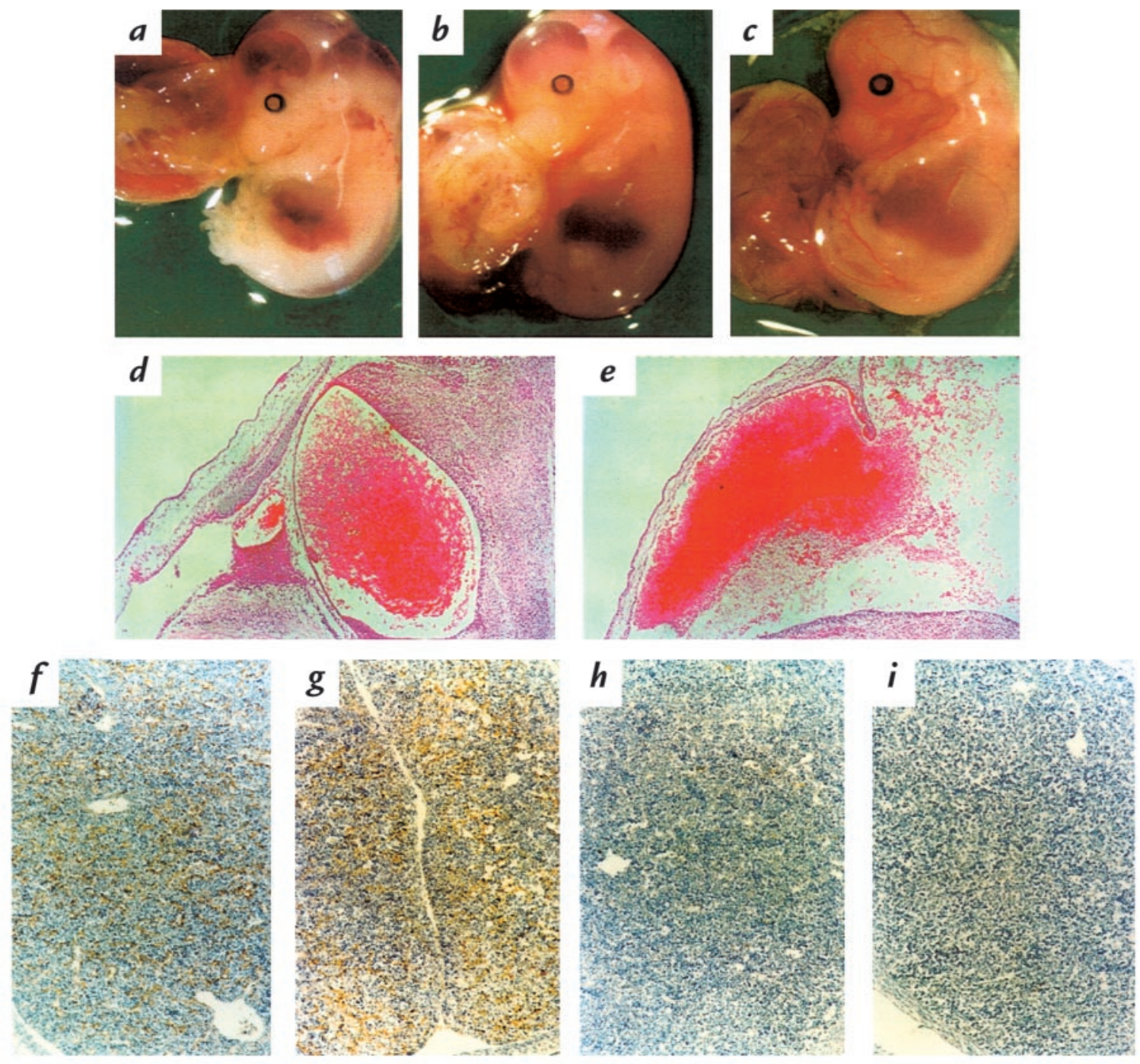

\section{Figure 3}

$(\boldsymbol{a}-\boldsymbol{c}) \mathrm{E} 14.5 \mathrm{FVII}^{+/+} / \mathrm{TFPI}^{\delta / \delta}(a), \mathrm{FVII}^{+/-} / \mathrm{TFPI}^{\delta / \delta}(b)$, and $\mathrm{FVII}^{-/-} / \mathrm{TFPI}^{\delta / \delta}(c)$ embryos. Massive hemorrhage and edema in the head, and general anemia, can be readily observed in the few $\mathrm{FVII}^{+/+} / \mathrm{TFPI}^{\delta / \delta}$ animals that survive to this age. $\mathrm{FVII}+/ / \mathrm{TFPI}^{\delta / \delta}$ embryos also present some hemorrhage in the head, whereas the $\mathrm{FVII}^{-/-} / \mathrm{TFPI}^{\delta / \delta}$ embryos show no abnormal bleeding events. ( $\boldsymbol{d}$ and $\boldsymbol{e}$ ) H\&E staining of E14.5 $\mathrm{FVII}^{+/-} / \mathrm{TFPI}^{\delta / \delta}(d)$ and $\mathrm{FVII}^{+/+} / \mathrm{TFPI}^{\delta / \delta}(e)$, demonstrating massive bleeding in the heads of both embryos but significant loss of brain matter surrounding the hemorrhage in the latter embryo. ( $f-i)$ Diffuse fibrin deposition (gold) is observed in $\mathrm{E} 14.5 \mathrm{FVII}^{+/-} / \mathrm{TFPI}^{\delta / \delta}(f)$ and $\mathrm{FVII}^{+/+} / \mathrm{TFPI}^{\delta / \delta}(g)$ liver sections, but not in $\mathrm{FVII}^{-/-} / \mathrm{TFPI}^{\delta / \delta}(h)$ or wild-type liver $(i)$.

$\mathrm{FVII}^{+/-} / \mathrm{TFPI}^{\delta / \delta}\left(\right.$ Fig. $3 d$ ) and $\mathrm{FVII}^{+/+} / \mathrm{TFPI}^{\delta / \delta}$ embryos (Fig. $3 e)$, although the pathologies observed in the $\mathrm{FVII}^{+/-} / \mathrm{TFPI}^{\delta / \delta}$ embryos were generally less severe than $\mathrm{FVII}^{+/+} / \mathrm{TFPI}^{\delta / \delta}$ embryos. Interstitial fibrin deposition in the livers of both $\mathrm{FVII}^{+/-} / \mathrm{TFPI}^{\delta / \delta}$ and $\mathrm{FVII}^{+/+} / \mathrm{TFPI}^{\delta / \delta}$ embryos was observed (Fig. 3 , $f$ and $g$ ). The $\mathrm{FVII}^{-1-} / \mathrm{TFPI}^{\delta / \delta}$ embryos demonstrated no abnormal bleeding or clotting events by $\mathrm{H} \& \mathrm{E}$ or antifibrin(ogen) staining (Fig. 3h), as observed with the wild-type mice (Fig. $3 i$ ). All other organs appeared normal.

Taken together with the postnatal data, the survival rate of $\mathrm{TFPI}^{\delta / \delta}$ embryos and mice clearly depends on the level of FVII. As the FVII level decreases from 100\% $\left(\mathrm{FVII}^{+/+}\right)$to $50 \%\left(\mathrm{FVII}^{+/-}\right)$to $0 \%\left(\mathrm{FVII}^{-/-}\right)$, there is a concomitant increase in overall embryonic and postnatal life span. Conversely, the survival rate of $\mathrm{FVII}^{-/-}$mice is not affected by the presence of the $t f p i \delta$ gene (Table 1 ).
Measurement of embryonic FVII and TFPI activity levels and tfpi mRNA levels. FVII activity levels were measured in E17.5 plasma (Table 1). Differences in the TFPI genotype did not significantly affect the FVII activity level of the $\mathrm{FVII}^{+/+}$mice, which ranged from $9 \%$ to $17 \%$ of adult wildtype FVII activity. FVII activity levels in the plasma of $\mathrm{FVII}^{-/-}$embryos were undetectable $(\leq 0.05 \%$ of adult levels), regardless of the TFPI genotype.

TFPI activity levels were measured in E17.5 and E11.5 plasma (Table 1). TFPI activity in E17.5 wild-type embryos was $200 \%$ to $300 \%$ that of adult mice. TFPI activity levels in pooled E11.5 wild-type plasma were approximately $30 \%$ of adult wild-type plasma. TFPI activity levels in $\mathrm{TFPI}^{+} / \delta$ plasma was approximately $50 \%$ that of wild-type littermates; however, no TFPI was detectable in any of the TFPI ${ }^{\delta / \delta}$ embryos at E17.5, regardless of the level of FVII.

Northern hybridizations of E9.5 yolk sacs were per- 
formed using the murine tfpi cDNA as a probe. A strong signal was observed from total RNA of pooled wild-type E9.5 yolk sacs compared with the adult heart RNA standard. As expected, a signal of approximately half the intensity and lower molecular weight was observed from total RNA of pooled TFPI ${ }^{\delta / \delta} \mathrm{E} 9.5$ yolk sacs. An hprt probe, used to standardize the amount of RNA loaded into each lane, demonstrated that a similar amount of RNA was analyzed.

\section{Discussion}

Recent findings in an increasing number of murine models of coagulation factor deficiencies have provided new insights into the role of hemostasis during embryonic development. Mice lacking TF (14-16), FV (17), prothrombin $(18,19)$, or thrombin receptor $(20)$ suffer embryonic lethal phenotypes of variable penetrance. However, mice deficient in FVII (9), FVIII (21), FIX (22), and fibrinogen (23) survived embryogenesis but suffered from a range of postnatal hemorrhagic diatheses.

The fact that no individuals with a TFPI deficiency have been identified provided the interest to generate a model of TFPI deficiency in mice and to examine the consequences of such a loss (10). Deletion of the Kunitz-1 domain was sufficient to eliminate the regulatory effect of TFPI on the FVIIa/TF complex. Interestingly, embryos homozygous for the $t f i^{\delta}$ genotype expired at times between E9.5 and birth. Although the original study indicated that no TFPI-null animals $\left(\mathrm{TFPI}^{\delta / \delta}\right)$ were born, since then, a small number have been identified but were found dead immediately after birth. Similar results were also obtained in the present study. Late-gestation $\mathrm{FVII}^{+/+} / \mathrm{TFPI}^{\delta / \delta}$ embryos displayed normal organ development but were stunted in growth and showed signs of disseminated intravascular coagulation (DIC). Yolk sac hemorrhage and circulatory collapse were found in earlystage $\mathrm{FVII}^{+/+} / \mathrm{TFPI}^{\delta / \delta}$ embryos, but whether this loss of vascular integrity was due to the lack of TFPI-mediated FVIIa/TF regulation or related to another, unknown function of TFPI could not be determined. This mechanistic issue was partly addressed in this study via the production of mice heterozygous in both FVII and TFPI and subsequent breeding to produce mice doubly deficient in FVII and TFPI.

Genotypic analysis of a large number of neonatal and E17.5 embryos produced from double heterozygous crosses clearly demonstrated that TFPI ${ }^{\delta / \delta}$ mice with an additional total FVII deficiency were rescued from the intrauterine death observed in $\mathrm{TFPI}^{\delta / \delta}$ mice. These $\mathrm{FVII}^{-/} / \mathrm{TFPI}^{\delta / \delta}$ mice developed normally in utero and survived to birth but suffered from the same fatal postnatal bleeding events as $\mathrm{FVII}^{-/-} / \mathrm{TFPI}^{+/+}$mice. These results indicate that embryonic FVII activity is involved in the mechanism of intrauterine lethality of TFPI ${ }^{\delta / \delta}$ mice. Conceivably, failure to downregulate FVIIa/TF activity in E9.5 embryos resulted in potentially lethal elevated levels of activated coagulation factors. Although previous studies have shown the presence of $f V I I \mathrm{mRNA}$ in the embryo and yolk sac at E9.5, it would now appear that these levels of FVII are in fact functionally important in $\mathrm{FVII}^{+/+}$mice.

As expected from the postnatal analyses, E17.5 $\mathrm{FVII}^{-/-} / \mathrm{TFPI}^{\delta / \delta}$ embryos were alive and normally developed. The rescue of the lethal TFPI ${ }^{\delta / \delta}$ phenotypes by a concomitant FVII deficiency allowed measurement of TFPI activity from these embryos, a determination that could not be made in the original study of the single $\mathrm{TFPI}^{\delta / \delta}$ deficiency because the majority of the embryos did not survive to this stage. Indeed, this particular $t f p i$ gene modification, as predicted, resulted in a gene product $\left(\mathrm{TFPI}^{\delta / \delta}\right)$ that could not inhibit FVIIa/TF activity. In addition, in contrast to the postnatal data, $\mathrm{FVII}^{+/-} / \mathrm{TFPI}^{\delta / \delta}$ embryos were present at the expected mendelian distribution. Thus, a $50 \%$ reduction in the FVII level also rescued the TFPI $I^{\delta / \delta}$ embryos from early intrauterine death. These $\mathrm{FVII}^{+/-} / \mathrm{TFPI}^{\delta / \delta}$ embryos were alive with normally developed organs. However, thrombosis and hemorrhage from occluded vessels in the brain led to subsequent necrosis of surrounding tissue, as observed via H\&E staining and antifibrin(ogen) immunostaining. Diffuse fibrin deposition in the interstitia of the liver was also observed, and additional signs of DIC were evident in the kidneys after birth. Similar DIC was observed in brain, liver, and kidney in the few $\mathrm{FVII}^{++} / \mathrm{TFPI}^{\delta / \delta}$ animals that survived to E17.5. Surprisingly, the abnormalities in $\mathrm{FVII}^{+/-} / \mathrm{TFPI}^{\delta / \delta}$ embryos appeared as early as E9.5, although the phenotype was significantly less severe compared with the $\mathrm{FVII}^{+/+} / \mathrm{TFPI}^{\delta / \delta}$ mice. By E14.5, these latter embryos already exhibited significant coagulation in brain and liver. Their full mendelian representation at E17.5 suggests that although the characteristics exhibited at E9.5 are similar to the single TFPI ${ }^{8 / \delta}$ modification, the decrease to half the level of FVII is sufficient to ensure rescue at $\mathrm{E} 9.5$ when embryos with the $\mathrm{FVII}^{+/+} / \mathrm{TFPI}^{\delta / \delta}$ genotype begin to expire. The significance of the E9.5 yolk sac tfpi mRNA levels demonstrates a likely requirement for this inhibitor during embryogenesis. This is substantiated by the fact that E11.5 and E17.5 embryos possess TFPI plasma activity levels of $30 \%$ and $300 \%$ of adult wild-type mice, respectively.

Finally, all the data obtained to date suggest that the cause of the early intrauterine death in $\mathrm{FVII}^{+/+} / \mathrm{TFPI}^{\delta / \delta}$ embryos may be due to an unfettered FVIIa/TF activity and that the removal of that source of activity, via the complete loss of embryonic FVII, resulted in a rescue of this phenotype. However, the exact mechanism by which FVIIa/TF activity produces early death remains unclear. Uncontrolled coagulation is one possible cause of death; however, the fact that fibrin deposition was observed in only one blood lake of several $\mathrm{FVII}^{+/+} / \mathrm{TFPI}^{\delta / \delta} \mathrm{E} 10.75$ yolk sacs examined suggests that the presence of fibrin is a result, but not a cause, of the phenotype. This rare observation demonstrates that fibrin formation, and thus hemostasis, can occur as early as E10.75dpc. However, formation of fibrin, in itself, is not required for embryogenesis (23). The more likely cause of death would either be the toxic effects of the coagulation enzymes themselves, or the consumption of clotting factors, resulting in diminished generation of FXa and/or thrombin. It is very likely that the presence of thrombin and FXa are required in this regard for several other functions related to cell signaling processes in which they are involved.

The results support the following conclusions regarding FVII levels in early-stage embryos. First, although FVII levels in E9.5 embryos were below the range of 
detection by available assays (9), physiologically/pathologically relevant levels of this protein must be expressed at this time, because deletion of its gene (and concomitant absence of FVII) rescues the lethality associated with the TFPI ${ }^{\delta / \delta}$ genotype. Furthermore, if transfer of maternal FVII to the embryo occurs, the level of maternal FVII in early-stage embryos is insufficient to cause a coagulopathy in $\mathrm{TFPI}^{\delta / \delta}$ mice, because the loss of embryonic FVII prevents intrauterine mortality in these animals.

\section{Acknowledgments}

The authors thank Mieke DeWit and Ivo Cornelissen for technical support. These studies were supported by grants HL19982 (to F.J. Castellino) and HL-34462 (to G.J. Broze) from the National Institutes of Health, a grant from the W.M. Keck Foundation (to F.J. Castellino), and by the Kleiderer/Pezold Family Endowed Professorship (to F.J. Castellino). J.C.Y. Chan was supported by the Raymond C. Tower and Kleiderer-Pezold Graduate Fellowships of the University of Notre Dame.

1. Wun, T.C., et al. 1988. Cloning and characterization of a cDNA coding for the lipoprotein-associated coagulation inhibitor shows that it consists of three tandem Kunitz-type inhibitory domains. J. Biol. Chem. 263:6001-6004

2. Girard, T.J., et al. 1989. Functional significance of the Kunitz-type inhibitory domains of lipoprotein-associated coagulation inhibitor. Nature. 338:518-520.

3. Wesselschmidt, R., et al. 1993. Structural requirements for tissue factor pathway inhibitor interactions with factor Xa and heparin. Blood Coagul. Fibrinolysis. 4:661-669.

4. Enjyoji, K., Miyata, T., Kamikubo, Y., and Kato, H. 1995. Effect of heparin on the inhibition of factor Xa by tissue factor pathway inhibitor. A segment, Gly212-Phe243, of the third Kunitz domain is a heparin binding site. Biochemistry. 34:5725-5735.

5. Broze, G.J., Jr. 1995. Tissue factor pathway inhibitor and the revised theory of coagulation. Annu. Rev. Med. 46:103-112.

6. Sandset, P.M., Warn-Cramer, B.J., Maki, S.L., and Rapaport, S.I. 1991. Immunodepletion of extrinsic pathway inhibitor sensitizes rabbits to endotoxin-induced intravascular coagulation and the generalized Schwartzman reaction. Blood. 78:1496-1502.

7. Sandset, P.M., et al. 1991. Depletion of extrinsic pathway inhibitor (EPI) sensitizes rabbits to disseminated intravascular coagulation induced with tissue factor: evidence supporting a physiologic role for EPI as a natural anticoagulant. Proc. Natl. Acad. Sci. USA. 88:708-712.

8. Ragni, M.V., Lewis, J.H., Spero, J.A., and Hasiba, U. 1981. Factor VII deficiency. Am. J. Hematol. 10:79-88.

9. Rosen, E., et al. 1997. Mice lacking factor VII develop normally but suffer fatal perinatal bleeding. Nature. 390:290-294

10. Huang, Z.-F., Higuchi, D., Lasky, N., and Broze, G.J., Jr. 1997. Tissue factor pathway inhibitor gene disruption produces intrauterine lethality in mice. Blood. 90:944-951.

11. Idusogie, E., et al. 1996. Nucleotide structure and characterization of the murine blood coagulation factor VII gene. Thromb. Haemost. 76:957-964.

12. Carmeliet, P., et al. 1994. Physiological consequences of loss of plasminogen activator gene function in mice. Nature. 368:419-424.

13. Carmeliet, P., et al. 1993. Plasminogen activator inhibitor-1 gene-deficient mice. II. Effects on hemostasis, thrombosis, and thrombolysis. J. Clin. Invest. 92:2756-2760.

14. Carmeliet, P., et al. 1996. Role of tissue factor in embryonic blood vessel development. Nature. 383:73-75.

15. Bugge, T.H., et al. 1996. Fatal embryonic bleeding events in mice lacking tissue factor, the cell-associated initiator of blood coagulation. Proc. Natl. Acad. Sci. USA. 93:6258-6263.

16. Toomey, J.R., et al. 1996. Targeted disruption of the murine tissue factor gene results in embryonic lethality. Blood. 88:1583-1587.

17. Cui, J.S., et al. 1996. Fatal haemorrhage and incomplete block to embryogenesis in mice lacking coagulation factor V. Nature. 384:66-68.

18. Sun, W.Y., et al. 1998. Prothrombin deficiency results in embryonic and neonatal lethality in mice. Proc. Natl. Acad. Sci. USA. 95:7597-7602.

19. Xue, J.C., et al. 1998. Incomplete embryonic lethality and fatal neonatal hemorrhage caused by prothrombin deficiency in mice. Proc. Natl. Acad. Sci. USA. 95:7603-7607.

20. Connolly, A.J., et al. 1996. Role of the thrombin receptor in development and evidence for a second receptor. Nature. 381:516-519.

21. Bi, L., et al. 1995. Targeted disruption of the mouse factor VIII gene produces a model of haemophilia a. Nat. Genet. 10:119-121.

22. Lin, H.F., et al. 1997. A coagulation factor IX-deficient mouse model for human hemophilia B. Blood. 90:3962-3966.

23. Suh, T.T., et al. 1995. Resolution of spontaneous bleeding events but failure of pregnancy in fibrinogen-deficient mice. Genes Dev. 9:2020-2030. 